LETTER TO JMG

\title{
Identification of a new locus for isolated familial keratoconus at 2 p24
}

\author{
H Hutchings, H Ginisty, M Le Gallo, D Levy, F Stoësser, J F Rouland, J L Arné, M H Lalaux, P Calvas, \\ M P Roth, A Hovnanian, F Malecaze
}

$\mathrm{K}$ eratoconus (KC; MIM 148300) is a non-inflammatory corneal thinning disorder. Progressive thinning and protrusion of the cornea lead to loss of visual acuity for which the only effective treatment is corneal transplantation. The estimated prevalence of KC is $1-4$ per 2000 in the general population. ${ }^{1}$ The age of onset is often at puberty, and the disorder is progressive until the third or fourth decade of life when it usually arrests. KC is a major cause of corneal transplantation in developed countries.

The cause of KC is still unknown. Histological observations have demonstrated degradation of the corneal epithelium basal membrane, diminution of the number of collagen fibrils, thinning of the corneal stroma, and keratocyte apoptosis. $^{23}$ Biochemical studies describe increased activity of metalloproteinases (MMP-2 and MMP-9) and lower expression of protease inhibitors such as $\alpha$ l-protease inhibitor. $^{45}$

Sporadic KC is the most common presentation; however, a positive familial history has been reported in at least $6-10 \%$ of patients. ${ }^{1}$ Twin studies performed since the advent of modern computerised videokeratoscopy have reported four monozygotic pairs concordant for $\mathrm{KC}$ and two monozygotic pairs which were discordant, ${ }^{6-9}$ suggesting a genetic component for KC. Keratoconus prevalence in first degree relatives of $\mathrm{KC}$ patients is significantly higher than in the general population, demonstrating familial aggregation of the trait. ${ }^{10}{ }^{11}$ Most published studies have suggested autosomal dominant inheritance of $\mathrm{KC}$ with incomplete penetrance or variable expression. ${ }^{12}$ Autosomal recessive inheritance as well as rare cases of $\mathrm{X}$ linked inheritance have also been described. ${ }^{10}{ }^{13}$ In some rare cases, KC is associated with other genetic disorders such as trisomy 21, atopy, and Leber congenital amaurosis. ${ }^{14} 15$

KC gene localisation efforts to date have been carried out in rare large families or in population isolates where genetic heterogeneity is minimised. Linkage studies include a genome scan of 20 Finnish families resulting in a multipoint LOD score of 4.1 on chromosome $16 q^{16}$ and a directed chromosome 21 scan in one large family with trisomy 21 leading to suggestive linkage. ${ }^{17}$ Association studies in eight unrelated patients in Tasmania have identified two putative loci on 18 p and 20q12. ${ }^{18}{ }^{19}$ However, these results have not yet led to the identification of a causative gene for familial KC and, although $\mathrm{KC}$ is present in all human populations, no studies have tested for linkage in a mixed outbred population.

In the present article, we identify a new candidate region at 2 p24 mapped by linkage and haplotype analysis in a heterogeneous population.

\section{METHODS}

\section{Families}

The study population included 253 members of 28 families recruited in France, Spain, and Guadeloupe (West Indies).

\section{Key points}

- Twenty eight pedigrees with isolated familial keratoconus (MIM 148300) were investigated.

- A genome-wide search mapped a new locus for keratoconus to chromosome 2 p24 with a maximal HLOD score of 5.13. Analysis of key recombination events placed the keratoconus locus in a $1.69 \mathrm{Mb}$ region flanked by markers D2S305 and D2S2373. Linkage to all other known keratoconus loci on chromosomes 3, 16, 20, and 21 was excluded.

- This candidate region contains eight known genes and 10 Acembly gene predictions.

- This study reports the first genome-wide scan in an outbred population (Caucasian, Arab, and Caribbean African) and is the first step in the positional cloning of a keratoconus gene.

There were 112 affected and 104 unaffected individuals; the other 37 individuals were of undetermined phenotype. Families were of European, Arab, and Caribbean African descent. All pedigrees had a minimum of two members who met the definition of clinical $\mathrm{KC}^{20}$ and no other recognised genetic disease segregated in these families. We performed ophthalmic examination of all the members of the 28 families using videokeratographic evaluation as described previously. ${ }^{11}$ KC was defined according to Rabinowitz's KISA\% inde ${ }^{20}$ : patients with a KISA\% over 300 have clinical $\mathrm{KC}$, patients with a KISA\% between 100 and 300 may have forme fruste $\mathrm{KC}$ and were considered as being of an undetermined phenotype, and patients with a KISA\% under 100 are unaffected. Children under the age of 16 were considered of unknown phenotype unless clinical KC was observed.

This study was approved by the ethical committee "Toulouse 2" according to French law, and informed consent was obtained from each patient.

\section{Microsatellite genotyping}

Venous blood samples were collected in EDTA for DNA extraction according to standard methods. ${ }^{21}$ Genotyping was performed in two successive stages. An initial set of seven informative families (88 individuals of Caucasian and Arab origin) composed of both affected and unaffected individuals was genotyped with the ABI PRISM Linkage Mapping Set of microsatellite markers, version 2 (Applied Biosystems, Foster City, CA, USA). While the first analysis was underway, additional families with $\mathrm{KC}$ were recruited. The total sample

Abbreviations: GDF-7, growth differentiation factor 7; KC, keratoconus 


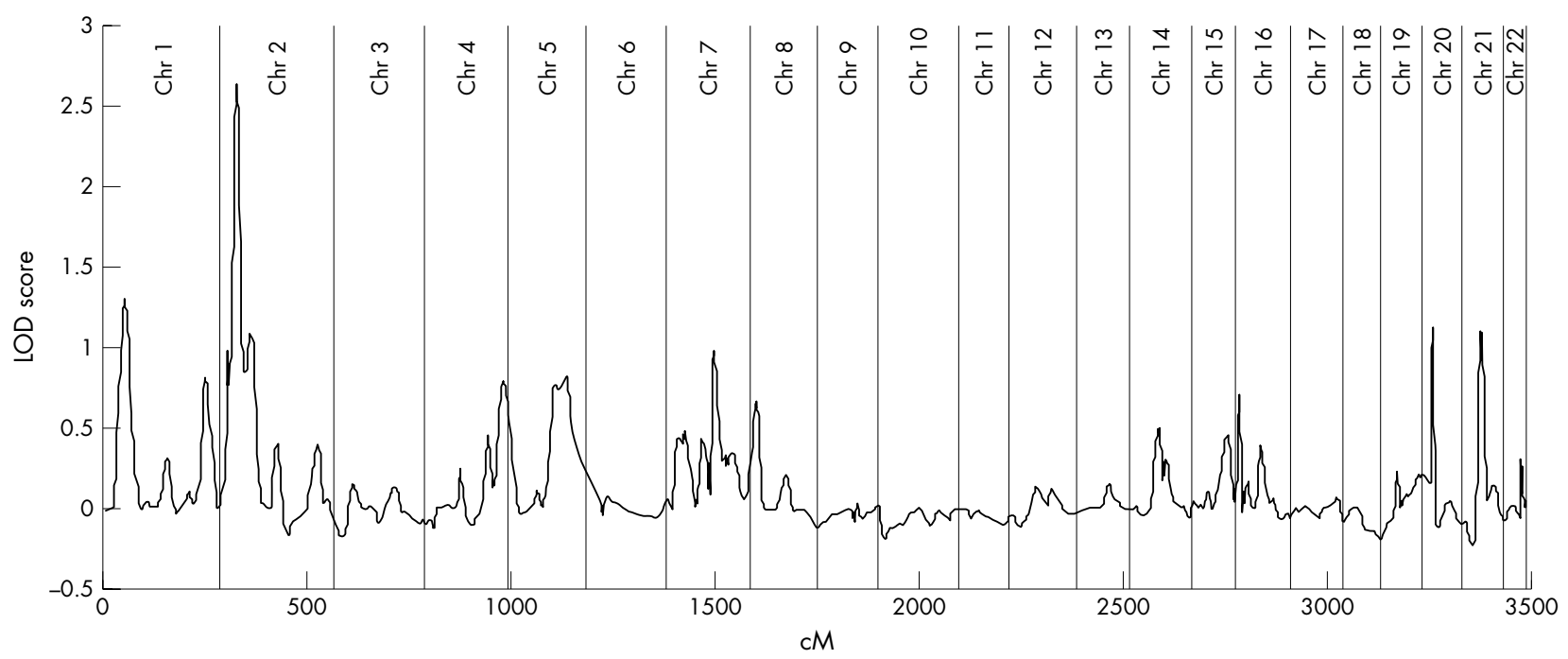

Figure 1 Linkage results of the genome-wide scan for KC with 382 autosomal markers in seven informative pedigrees. Multipoint LOD scores were calculated with Merlin. The genetic locations correspond to the Marshfield genetic map ${ }^{25}$ and are expressed in Kosambi $\mathrm{cM}$.

size was thus increased to 28 informative pedigrees, consisting of 112 affected and 104 unaffected members available for genotyping. The second set of 21 families was only genotyped with markers for the short arm of chromosome 2 .

All PCR reactions were carried out with 25 ng of genomic DNA as a template in a mixture of $1 \times$ Applied Biosystems PCR buffer II, $2.5 \mathrm{mM} \mathrm{MgCl}_{2}, 200 \mathrm{nM}$ of each dNTP, 5 pmol of each primer, and $0.1 \mu \mathrm{l}$ of AmpliTaq Gold polymerase (Applied Biosystems) in a final volume of $15 \mu$. The thermocycling conditions were $94^{\circ} \mathrm{C}$ for $10 \mathrm{~min}$, followed by 33 cycles at $94^{\circ} \mathrm{C}$ for $30 \mathrm{~s}, 53^{\circ} \mathrm{C}$ for $30 \mathrm{~s}$, and $72^{\circ} \mathrm{C}$ for $30 \mathrm{~s}$, followed by a final extension step at $72^{\circ} \mathrm{C}$ for $5 \mathrm{~min}$. PCR products were then pooled with regard to their size range and labelling and were analysed by denaturing electrophoresis on an ABI Prism 3100 DNA Sequencer (Applied Biosystems). The marker alleles were assigned with GENESCAN and GENOTYPER software (Applied Biosystems). A set of 36

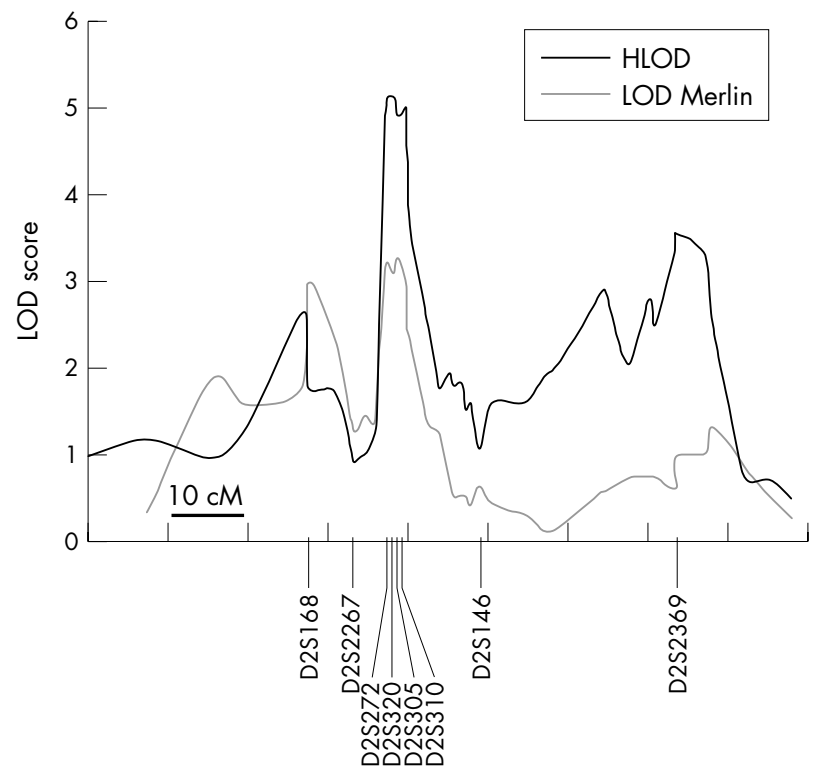

Figure 2 Results of multipoint linkage analysis with 48 microsatellite markers on chromosome $2 p$ showing non-parametric LOD (grey) and HLOD (black) scores for the dominant parametric model. additional markers obtained from online information was added for detailed analysis of the short arm of chromosome 2 .

\section{Statistical analysis}

Non-parametric multipoint linkage analysis for the genomewide screen was performed with the Merlin program..$^{22}$ Nonparametric linkage analysis concentrates on allele sharing between family members with the same phenotype. Merlin outputs both NPL all $\left(Z_{\text {lr }}\right)$ scores and Kong and Cox LOD scores $^{23}$ to test for allele sharing among affected individuals, with their asymptotic p values. All Mendelian inheritance and genotype errors were checked using Merlin and resolved. Allele frequencies were calculated in unrelated founders with Merlin. Multipoint parametric linkage analysis, allowing for heterogeneity, was performed with Genehunter, version 2.1. ${ }^{24}$ The frequency of the putative $\mathrm{KC}$ gene was set at 0.0006 . No sex difference was assumed. Penetrances were $0.001,0.5$, and 0.8 , respectively, for the $1 / 1,1 / 2$, and $2 / 2$ genotypes ( 1 , normal allele; 2 , mutated allele; a penetrance of 0.001 for the 1/l genotype corresponds to the prevalence of sporadic KC). The marker mapping information was obtained from the Marshfield map ${ }^{25}$ and the NCBI database (Online Mendelian Inheritance in Man (OMIM), http://www.ncbi.nlm.nih.gov/ entrez/query.fcgi?db = OMIM). We used Genehunter for haplotype reconstruction. The program reports the most likely haplotype, marking crossovers and highlighting double crossovers. It also indicates regions of haplotype uncertainty.

\section{RESULTS}

\section{Assignment of the $\mathrm{KC}$ gene to $2 \mathrm{p} 24$}

We undertook a genome-wide search for linkage in an initial set of seven families whose results are displayed in fig 1. Non-parametric analysis by Merlin found suggestive linkage on chromosome $2 \mathrm{p}$ with a LOD score of $2.64\left(\mathrm{Z}_{\mathrm{lr}}=4.91\right.$, $\mathrm{p}<10^{-5}$ ) for marker D2S305. No other LOD scores $>1.5$ were observed. In particular, no evidence for linkage between KC and markers on the chromosome arms 16q, 18p, or 2lq was observed.

The full data set of 28 families was then typed for 36 additional markers across a $80 \mathrm{cM}$ region spanning D2S319 to D2S286. Marker order is displayed in table 1. When all families were analysed we obtained suggestive evidence of linkage with a maximum LOD score at D2S305 of 3.26 $\left(\mathrm{Z}_{\mathrm{lr}}=5.02, \mathrm{p}<10^{-5}\right)$ (fig 2, grey line). 
Table 1 Microsatellite marker order and genetic and physical distances on chromosome $2 p$

\begin{tabular}{|c|c|c|}
\hline Marker & cM (Marshfield map) & Mb (public location) \\
\hline D2S319 & 7.600 & 5.036 \\
\hline D2S2211 & 15.610 & 7.493 \\
\hline D2S162 & 20.030 & 8.882 \\
\hline D2S168 & 27.060 & 11.467 \\
\hline D2S2200 & 27.600 & - \\
\hline D2S131 & 31.200 & 13.389 \\
\hline D2S2267 & 33.310 & 13.757 \\
\hline D2S149 & 34.040 & 14.415 \\
\hline D2S312 & 34.780 & 15.249 \\
\hline D2S2295 & 35.980 & 16.459 \\
\hline D2S2346 & 36.720 & 16.833 \\
\hline D2S272 & 37.380 & 16.851 \\
\hline D2S320 & 38.330 & 18.231 \\
\hline D2S305 & 38.870 & 19.403 \\
\hline D2S310 & 39.920 & 19.538 \\
\hline D2S2233 & 39.925 & 19.784 \\
\hline D2S175 & 39.930 & 19.926 \\
\hline D2S2342 & 40.200 & 20.314 \\
\hline D2S2150 & 40.470 & 20.516 \\
\hline D2S2373 & 42.650 & 21.097 \\
\hline D2S2221 & 44.090 & 23.198 \\
\hline D2S2168 & 45.300 & 25.063 \\
\hline D2S2303 & 45.830 & - \\
\hline $\mathrm{D} 2 \mathrm{~S} 174$ & 46.900 & 26.814 \\
\hline D2S2247 & 46.950 & 27.278 \\
\hline D2S 165 & 47.430 & 28.578 \\
\hline D2S2312 & 47.970 & 28.844 \\
\hline D2S146 & 49.040 & 29.566 \\
\hline D2S352 & 50.650 & 31.476 \\
\hline D2S367 & 54.960 & 34.415 \\
\hline D2S2186 & 57.220 & 37.047 \\
\hline D2S177 & 59.360 & 38.001 \\
\hline D2S2259 & 64.290 & 42.971 \\
\hline D2S2294 & 64.840 & 43.850 \\
\hline D2S2174 & 67.580 & 45.153 \\
\hline D2S391 & 70.310 & 46.386 \\
\hline D2S2227 & 71.140 & 47.244 \\
\hline D2S2316 & 73.605 & 51.067 \\
\hline D2S123 & 73.600 & 51.263 \\
\hline D2S2369 & 73.610 & 53.199 \\
\hline D2S378 & 77.430 & 57.278 \\
\hline D2S2183 & 77.970 & 59.077 \\
\hline D2S337 & 80.690 & 61.644 \\
\hline D2S147 & 82.290 & 64.139 \\
\hline D2S2368 & 85.480 & 67.188 \\
\hline D2S303 & 88.150 & 70.437 \\
\hline D2S2110 & 90.820 & 73.047 \\
\hline D2S286 & 94.050 & 75.317 \\
\hline
\end{tabular}

Since segregation of KC in our families seemed in agreement with autosomal dominant inheritance, we performed multipoint parametric analysis and applied a dominant model to our data. We set gene frequency of the familial form of $\mathrm{KC}$ at 0.0006 and applied penetrances of $0.001,0.5$, and 0.8 corresponding to the $1 / 1,1 / 2$, and $2 / 2$ genotypes. Allowing for genetic heterogeneity, we obtained a maximal HLOD score of 5.13 for $\alpha=0.52$ ( $\alpha=$ fraction of families used to obtain a maximum LOD score) at marker D2S320 (fig 2, black line). These results demonstrate significant linkage for $\mathrm{KC}$ at $2 \mathrm{p} 24$. Of note, the l-LOD-drop support interval around the maximum HLOD score, an approximate $90 \%$ confidence interval, included a region spanning D2S2346 to D2S2342 (including D2S305 and D2S320).

\section{Haplotype analysis}

Haplotypes were established with all 48 microsatellite markers given in table 1 . Since the mode of inheritance and the penetrance of $\mathrm{KC}$ have yet to be determined, we first examined the segregation of haplotypes at 2 p24 between affected individuals. We show that marker alleles cosegregated with the KC phenotype in 17 out of the 28 families

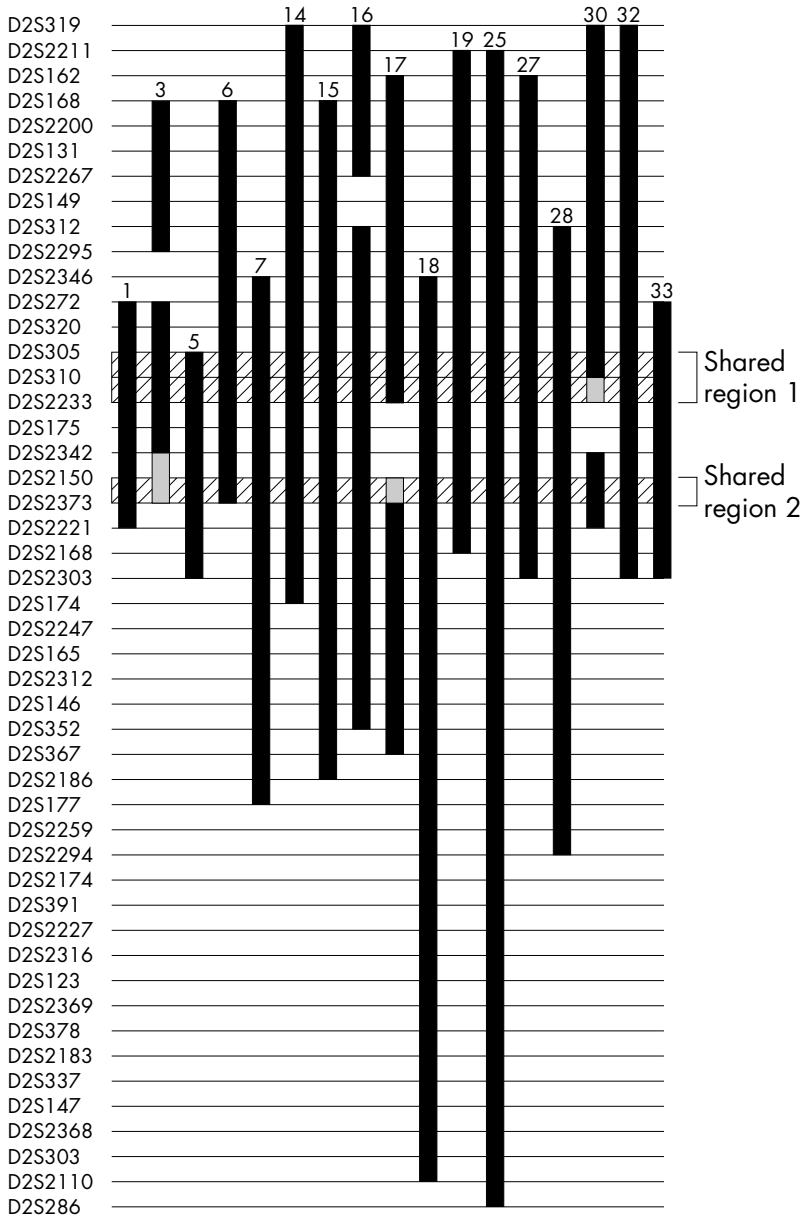

Figure 3 Haplotypes shared by the affected members of 17 of the 28 families. Black vertical bars delimit the largest shared haplotype among all affected members of each family. Grey sections denote regions where recombination events could not be localised exactly. Haplotypes extend up to but do not include markers at the limits of the bars. Pedigree numbers are displayed above each vertical line. Two regions were shared by all 17 families: D2S305-D2S2233 and D2S2150-D2S2373.

(fig 3). Haplotypes differed between families. Haplotypes extend up to, but do not include, markers at the ends of the bars. Critical meiotic recombinants could be identified in families 3, 5, and 6. Integration of healthy individuals changed haplotypes in families 17 and 30, where a gap was found in the shared haplotype due to a double recombination event in a healthy sibling. Two intervals were therefore shared by all affected members of the 17 families (hatched area in fig 3). Detailed genotype data for families 3, 5, 6, 17, 30 , and 33 are shown for 12 markers spanning the shared region in figs $4 \mathrm{~A}$ and $4 \mathrm{~B}$. The first is telomeric to marker D2S2233 and centromeric to D2S305, while the second is telomeric to marker D2S2373 and centromeric to D2S2150. The overall interval covers a region of $\sim 3.78 \mathrm{cM}(1.69 \mathrm{Mb})$. The first interval (D2S2233-D2S305) extends over $0.4 \mathrm{Mb}$ and the second interval (D2S2373-D2S2150) extends over $0.5 \mathrm{Mb}$.

\section{Search for candidate genes or transcripts}

According to data available on the National Center for Biotechnology Information (http://www.ncbi.nlm.nih.gov/ entrez/query.fcgi?db = OMIM), UCSC Genome Browser (http://www.genome.ucsc.edu/cgi-bin/hgGateway), and Ensembl (http://www.ensembl.org/) databases, eight previously 

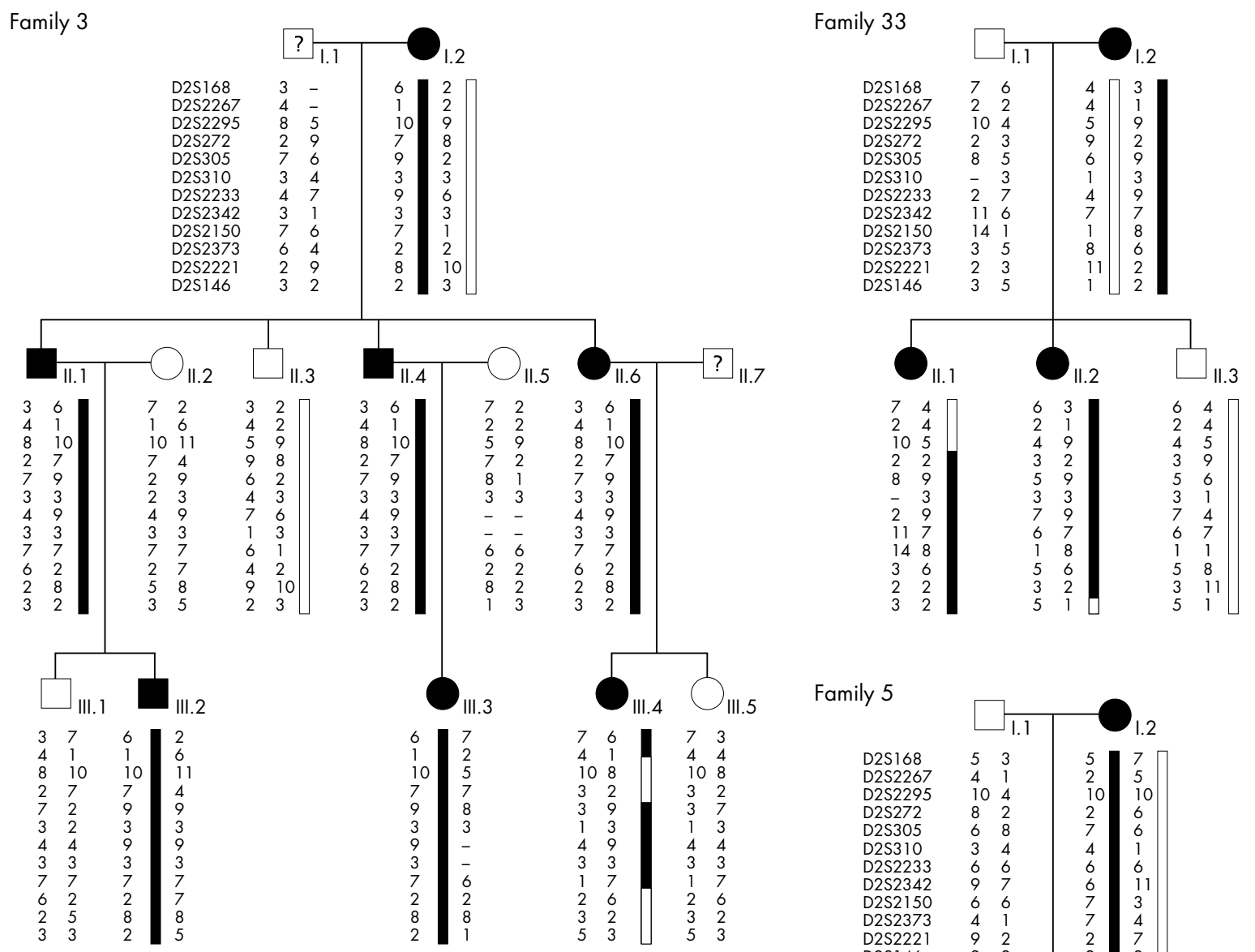

Figure 4A Pedigrees of families 3, 5, and 33 delimiting the chromosome 2 regions and haplotypes of markers spanning this $\mathrm{KC}$ locus. man; $\square$ unaffected man; affected woman; $\bigcirc$ unaffected woman; / deceased; ? unknown phenotype; black vertical line: haplotype that segregated with disease in each family. Grey sections denote regions where recombination events could not be localised exactly. Genotypes for only 12 (out of 48 ) microsatellite markers are shown.

identified genes were contained between markers D2S305 and D2S2373. These genes are OSR1, KIAA1336, MATN3, LAPTM4A, SDCl, PUMl, ARHB, FLJ14249, GDF-7, and FLJ21820 (fig 5). Also, 10 Acembly (http://www.humangenes. org/) spliced gene predictions have also been mapped to this region. When only the two shared intervals are considered, this list is reduced to the known genes OSRl, ARHB, FLJ14249, GDF-7, and FLJ21820, and the Acembly spliced gene predictions keekla, skylu, klodo, kerkla, klardo, plydo, and skeedo. Of this list, only ARHB (RhoB) and GDF-7 have a known cellular function (actin reorganisation and control of cell differentiation, respectively).

\section{DISCUSSION}

$\mathrm{KC}$ is the leading cause of corneal transplantation in developed countries. Therefore, geneticists are working to map the gene responsible for familial $\mathrm{KC}$ and so greatly increase the little knowledge we have of this pathology. The results of the present genome-wide linkage and refinement studies indicate that a major gene for $\mathrm{KC}$, responsible for 50 $60 \%$ of familial KC cases studied, is located within a $1.69 \mathrm{Mb}$ region (one of two small regions, both $<0.5 \mathrm{Mb}$ ) at $2 \mathrm{p} 24$.

We performed here a genome-wide scan in seven large KC families and found a suggestive level of linkage at $2 \mathrm{p} 24$. The divergence of the values obtained for the LOD score and the $Z_{\text {Ir }}$ statistic at this locus $(\mathrm{LOD}=2.64$ is only evidence suggestive of linkage, whereas $Z_{\mathrm{lr}}=4.91$ is generally accepted as significant evidence) is probably due to a skewed distribution of $Z_{1 \mathrm{r}}$ because of the small number of families included in this first step of the study (for detailed discussion see Kong and $\operatorname{Cox}^{23}$ ).

Refinement of the $2 \mathrm{p} 24$ region using a larger set of $28 \mathrm{KC}$ families resulted in a non-parametric LOD score curve with two peaks with a LOD score $>3$. Various hypotheses could 


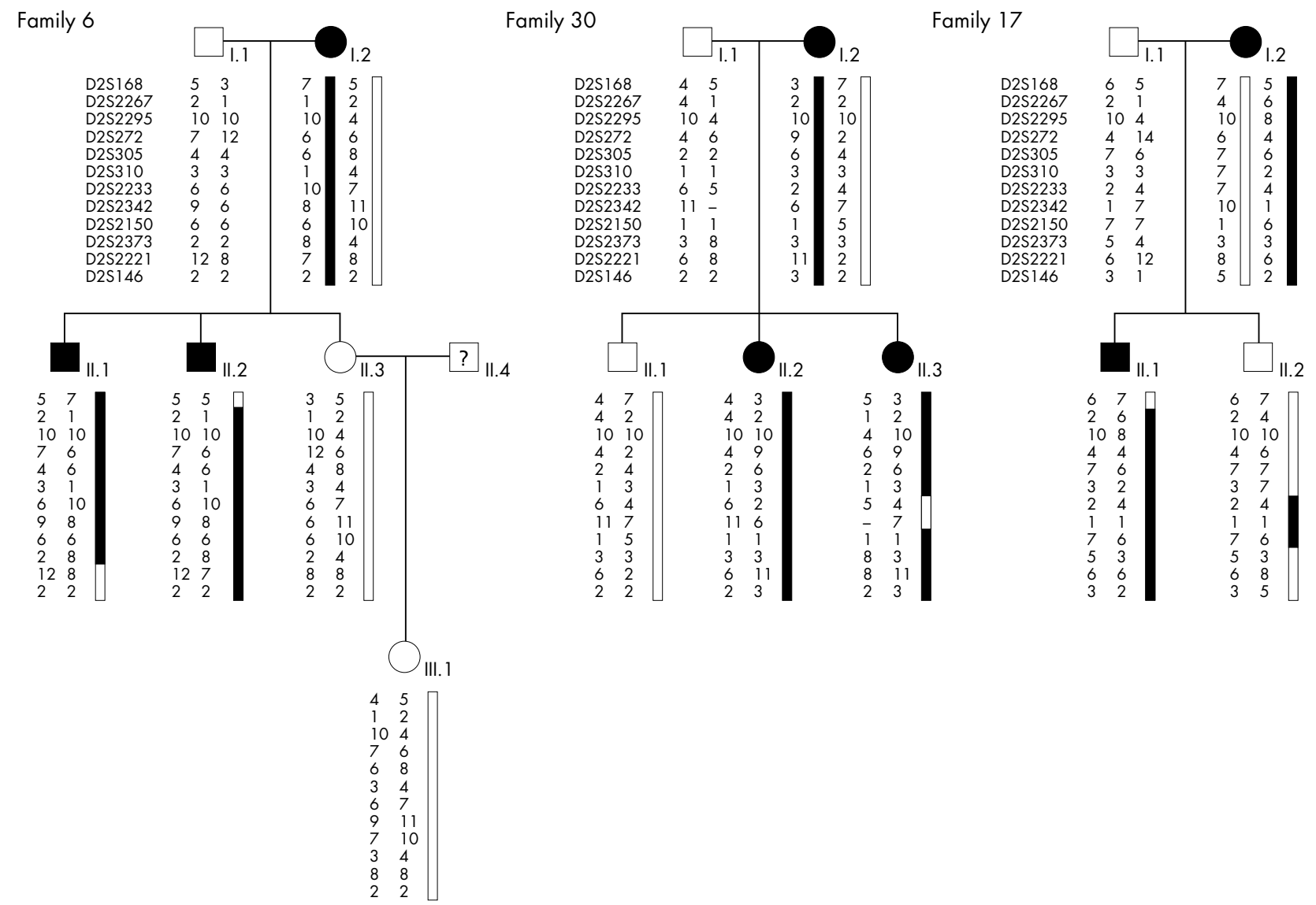

Figure 4B Pedigrees of families 6, 17, and 30 (see fig 4A legend).

explain the existence of these two peaks and are yet to be tested. First, one of the peaks could be artefactual, maybe due to the heterogeneity of the population and/or the phenotype. For example, linkage studies for asthma resulted in two peaks at 20pl3 separated by approximately $5 \mathrm{cM}$ with exactly the same LOD score values. ${ }^{26}$ Refinement of the phenotype used for these linkage studies supported only the region under the second peak and led to identification of mutations in the ADAM33 gene. It is possible that there are different phenotypes for $\mathrm{KC}$ that are for the moment clinically undistinguishable. Second, the two LOD peaks could be accounted for by the existence of two causal KC genes at the same locus. This has already been demonstrated in Griscelli syndrome where some patients were found to have no mutations in the MyoVa gene whilst haplotype analysis showed segregation at the same 15q21 locus. ${ }^{27}$ Finally mutations were discovered in RAB27A, $1.6 \mathrm{cM}$ distant from the MyoVa gene. ${ }^{28}$

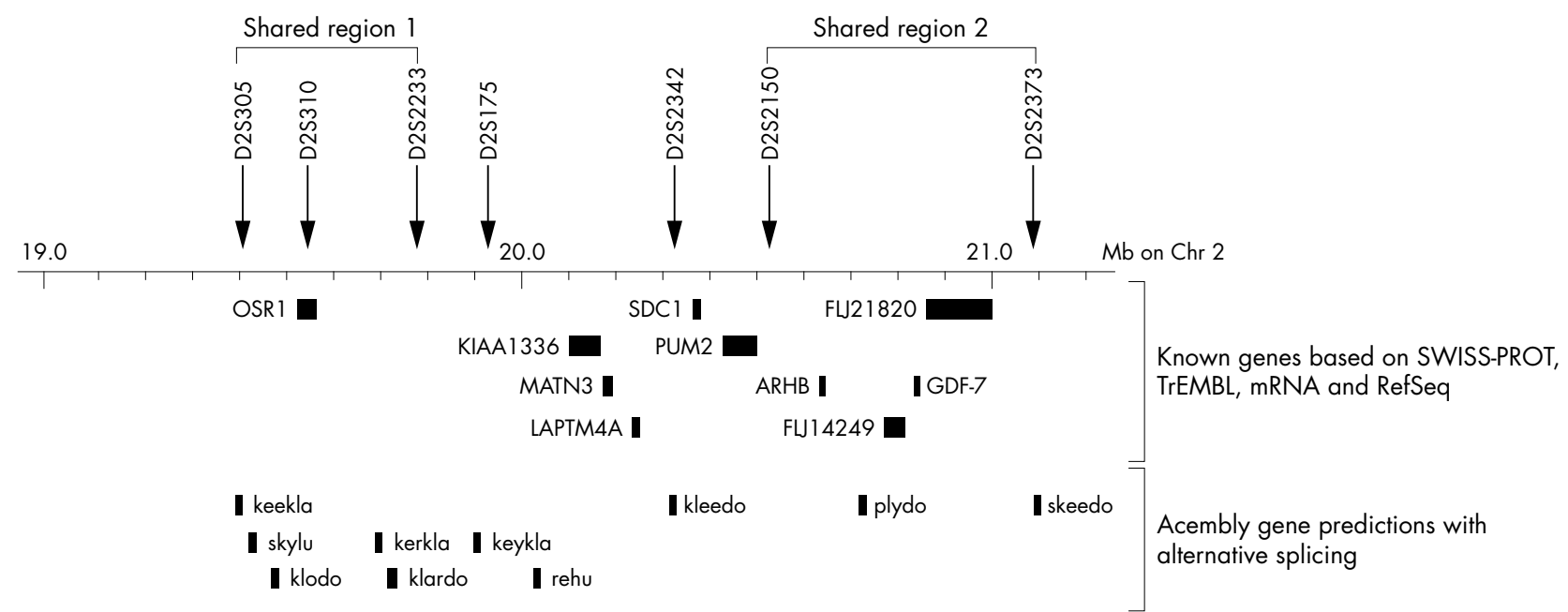

Figure 5 Genes localised in the KC candidate region according to UCSC Genome Browser and NCBI Mapviewer (http://www.ncbi.nlm.nih.gov/ mapview/). Distances are shown in Mb (public location). 
Since the beginning of our project, one group has published the results of their genome-wide scan suggesting the existence of a locus for familial $\mathrm{KC}$ on chromosome 16q22.3-q23.1 in a genetically isolated Finnish population. ${ }^{16}$ Mutations in the VSXl gene (20pll-q11), coding for a putative homeobox domain transcription factor have also been identified in patients suffering from KC. However these mutations were only found in $4.7 \%$ of $\mathrm{KC}$ cases which corresponds to approximately $1 \%$ of familial KC cases ${ }^{29}$ Two additional loci (20q12 and 18p) and a founder effect have also been identified by association studies. ${ }^{18} 19$ Nevertheless, these results are not in conflict with our data since a high level of genetic heterogeneity is suspected for familial KC, resulting in different loci segregating with the disease in various families or populations.

Despite the use of a fairly large population including several large families, we did not obtain clear evidence $(\mathrm{LOD}=3.26)$ of non-parametric linkage at commonly accepted statistical significance levels $(\mathrm{LOD}=3.3)$. The segregation of $\mathrm{KC}$ in the majority of our families seemed largely in agreement with a dominant Mendelian mode of inheritance with incomplete penetrance. In view of this and since genetic heterogeneity is suspected for KC, we applied a dominant model to obtain parametric HLOD scores. After analysis, we obtained a significant HLOD of 5.13 with $\alpha=0.52$.

Haplotype analysis also confirmed that a chromosomal region at 2 p24 segregated with the disease phenotype in 17 out of the 28 families. This corresponds to $60 \%$ of the families and is close to the $52 \%$ used by Genehunter to optimise the HLOD score (the difference is not statistically significant). The higher percentage obtained by haplotype analysis could be due to the fact that some of the unaffected individuals used by Genehunter carry the mutated allele but display no KC phenotype because of incomplete penetrance.

In families 3 and 5, single (individual 5.II.2) and double (individual 3.III.4) recombination events allowed us to narrow down the locus to a $1.69 \mathrm{Mb}$ interval. In families 17 and 30, inclusion of an unaffected sibling with a double recombination event in the haplotype analysis divided the candidate region into two smaller regions. This could lead to several different explanations. First, both apparently healthy siblings in families 17 and 30 (both are over the normal KC onset age) could be carriers of the causal mutation but display no phenotype. Second, the natural occurrence of two such double recombinations seems very unlikely and this event could perhaps be explained by spurious marker order. However, we observe a rather high recombination rate in this region in our families (95 recombination events for 97 meioses over the $80 \mathrm{cM}$ region and $40 \%$ of these recombination events are restricted to two $5 \mathrm{cM}$ regions surrounding markers D2S2373 and D2S367) and several small double recombinations. Microsatellite markers in the D2S272D2S2221 region were regenotyped and previously observed double recombination events were validated. This chromosomal region contains numerous repetitive sequences (Alu, LINE SINE) which could perhaps influence the stability of the 2 p24 region and should be taken into account for positioning candidate regions.

We conclude that we have identified a causative locus for familial KC at 2 p24 which predisposes to the disease in a significant proportion of the families. The fact that we discovered no common haplotype between the various linked families is not surprising since no relationship is known of between these families and the microsatellite markers used for haplotype analysis are probably not dense enough to prove a founder effect.

This new KC locus covers a physical distance of $1.69 \mathrm{Mb}$ which was further reduced to $0.9 \mathrm{Mb}$ following the analysis of informative family 17. Eight known genes and 10 Acembly gene predictions have been mapped within its boundaries. Functional candidate KC genes have been proposed up to now on the basis of histological analysis. These include corneal collagens, proteinases, proteinase inhibitors, and interleukin-l associated proteins. Collagen $6 \mathrm{Al}$ was a major candidate after linkage; it was found on chromosome 21q in a large pedigree with Down syndrome, but this chromosome has been entirely sequenced without the discovery of any mutation. ${ }^{30}$ Metalloproteinases are another candidate gene group; MMP-2 and MMP-9 have both been shown to be upregulated in patients with KC. ${ }^{5}{ }^{12}{ }^{31}$ MMP-9 is located near the 20q12 locus identified in Tasmanians and MMP-2 is near the 16q locus in a Finnish population, but both have since been excluded as candidate genes. ${ }^{16} 19$

Of the five known genes (OSR1, RhoB, GDF-7, FLJ21820, and FLJ14249) in the two regions with shared haplotypes, none are known to be involved in human disease. OSRl encodes odd-skipped related 1 , a putative transcription factor which possesses a homeobox domain. RhoB is a possible candidate gene since it stimulates actin stress fibre formation and focal adhesion points. Mutations in RhoB could explain structural defects observed in $\mathrm{KC}$ corneas. However, this gene is expressed in many other tissues where its functions are highly important, so it seems unlikely that mutations would lead to symptoms restricted to the cornea. GDF-7 (growth differentiation factor 7) is a good candidate gene due to the existence of TGF- $\beta$ domains in its sequence. TGF- $\beta$ and related proteins have already been investigated for their possible implication in KC because of their importance in the corneal epithelium but to no avail. However, probable roles for GDF-7 have been identified so far in the rhesus monkey neocortex, in seminal vesicle differentiation, and in commissural interneuron growth in the mouse spinal cord where dysfunction of this protein leads to aberrant development of the mouse embryo. ${ }^{32-34}$ Therefore, it seems improbable that a gene essential to nervous system development could confer only a corneal phenotype when mutated in man. The functions of FLJ21820 and FLJ14249 remain unknown. The Acembly gene predictions correspond to spliced Image clones and indicate the localisation of yet unknown genes. Analysis of the expression of all these candidate genes is underway and genomic sequences are being screened for mutations.

Identification of a causative KC gene will improve our understanding of this disease and should aid discovery of other familial KC genes. Comprehension of the molecular biology and biochemistry that underlie $\mathrm{KC}$ will be a first step towards new therapeutic strategies to slow and prevent this blindness disorder in both the familial and sporadic forms.

\section{ACKNOWLEDGEMENTS}

We would like to thank the families for their participation in this research.

\section{ELECTRONIC-DATABASE INFORMATION}

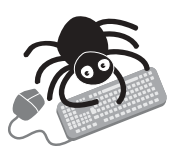

The URLs for data presented herein are as follows: Online Mendelian Inheritance in Man (OMIM), http:// www.ncbi.nlm.nih.gov/entrez/query.fcgi?db $=$ OMIM; NCBI Mapviewer, http://www.ncbi.nlm.nih. gov/mapview/; UCSC Genome Browser, http:// www.genome.ucsc.edu/cgi-bin/hgGateway; and Ensembl, http://www.ensembl.org/.

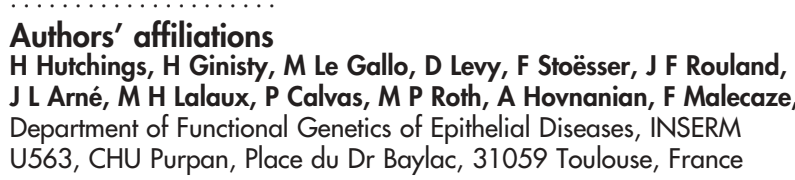

\section{Authors' affiliation}

H Hutchings, H Ginisty, M Le Gallo, D Levy, F Stoësser, J F Rouland, Department of Functional Genetics of Epithelial Diseases, INSERM U563, CHU Purpan, Place du Dr Baylac, 31059 Toulouse, France 
This work was supported by grants from INSERM, l'Association Retina France, l'association Valent Haüy, and the Délégation Régionale à la Recherche Clinique des Hôpitaux de Toulouse (2003-AOL No. 0303502). HH held a Fondation de France fellowship.

Competing interests: none declared

Correspondence to: François Malecaze, INSERM U563, Bâtiment B, CHU Purpan, Place du Dr Baylac, 31059 Toulouse, France; malecaze.fr@chu-toulouse.fr

Received 4 May 2004

Revised version received 19 July 2004

\section{REFERENCES}

1 Rabinowitz YS. Keratoconus. Surv Ophthalmol 1998;42:297-319.

2 Kenney MC, Nesburn AB, Burgeson RE, Butkowski RJ, Liubimov AV. Abnormalities of the extracellular matrix in keratoconus corneas. Cornea 1997; 16:345-51.

3 Kaldawy RM, Wagner J, Ching S, Seigel GM. Evidence of apoptotic cell death in keratoconus. Cornea 2002;21:206-9.

4 Ahn CS, McMahon T, Sugar J, Zhou L, Yue BY. Levels of alphal-proteinase inhibitor and alpha2-macroglobulin in the tear film of patients with keratoconus. Cornea 1999; 18:194-8.

5 Smith VA, Easty DL. Matrix metalloproteinase 2: involvement in keratoconus. Eur J Ophthalmol 2000;10:215-26.

6 Bechara SJ, Waring GO 3rd, Insler MS. eratoconus in two pairs of identical twins. Cornea 1996;15:90-3

7 Parker J, Ko WW, Pavlopoulos G, Wolfe PJ, Rabinowitz YS, Feldman ST. Videokeratography of keratoconus in monozygotic twins. J Refract Surg 1996:12:180-3.

8 McMahon TT, Shin JA, Newlin A, Edrington TB, Sugar J, Zadnik K. Discordance for keratoconus in two pairs of monozygotic twins. Cornea 1999; 18:444-51

9 Owens H, Watters GA. Keratoconus in monozygotic twins in New Zealand. Clin Exp Optom 1995;78:125-9.

10 Wang Y, Rabinowitz YS, Rotter JI, Yang H. Genetic epidemiological study of keratoconus: evidence for major gene determination. Am J Med Genet 2000;93:403-9.

11 Levy D, Hutchings H, Rouland JF, Guell J, Burillon C, Arné JL, Colin J, Laroche L, Montard M, Delbosc B, Aptel I, Ginisty H, Grandjean H, Malecaze F. Videokeratographic anomalies in familial keratoconus. Ophthalmology 2004; 111 1(5):867-74

12 Ihalainen A. Clinical and epidemiological features of keratoconus genetic and external factors in the pathogenesis of the disease. Acta Ophthalmol Suppl 1986;178:1-64.

13 Hammerstein $\mathrm{W}$. [Significance of the sex ratio in the determination of Xchromosomal heredity demonstrated on the clinical picture of keratoconus] (in German). Klin Monatsbl Augenheilkd 1971;159:602-8.

14 Elder MJ. Leber congenital amaurosis and its association with keratoconus and keratoglobus. J Pediatr Ophthalmol Strabismus 1994;31:38-40.

15 Gullen J, Butler HG. Mongolism (Down syndrome) and keratoconus. Br J Ophthalmol 1963;47:321-30.

16 Tyynismaa H, Sistonen P, Tuupanen S, Tervo T, Dammert A, Latvala T, Alitalo T. A locus for autosomal dominant keratoconus: linkage to 16q22.3 q23.1 in Finnish families. Invest Ophthalmol Vis Sci 2002;43:3160-4.

17 Rabinowitz YS, Zu H, Ang Y, Wang J, Rotter S, Pulst S. Keratoconus: nonparametric linkage analysis suggests a gene locus near the centromere on chromosme 21. Invest Ophthalmol Vis Sci 1999;40:S564.
18 Fullerton J, Paprocki P, Foote S, Mackie D, Williamson R, Forrest S. An association approach using eight affected individuals from Tasmania, Australia maps a locus of keratoconus. Am J Hum Genet 1999;65(suppl):81.

19 Fullerton J, Paprocki P, Foote S, Mackey DA, Williamson R, Forrest S. Identityby-descent approach to gene localisation in eight individuals affected by keratoconus from north-west Tasmania, Australia. Hum Genet 2002; 110:462-70.

20 Rabinowitz YS, Rasheed K. KISA\% index: a quantitative videokeratography algorithm embodying minimal topographic criteria for diagnosing keratoconus. J Cataract Refract Surg 1999;25:1327-35.

21 Sambrook J, Russell DW, eds. Molecular cloning: a laboratory manual, 3rd ed. Cold Spring Harbor, NY: Cold Spring Harbor Laboratory Press, 2001.

22 Abecasis GR, Cherny SS, Cookson WO, Cardon LR. Merlin-rapid analysis of dense genetic maps using sparse gene flow trees. Nat Genet 2002;30:97-101.

23 Kong A, Cox NJ. Allele-sharing models: LOD scores and accurate linkage tests. Am J Hum Genet 1997;61:1179-88.

24 Kruglyak L, Daly MJ, Reeve-Daly MP, Lander ES. Parametric and nonparametric linkage analysis: a unified multipoint approach. Am J Hum Genet 1996;58:1347-63.

25 Broman KW, Murray JC, Sheffield VC, White RL, Weber JL. Comprehensive human genetic maps: individual and sex-specific variation in recombination. Am J Hum Genet 1998:63:861-9.

26 Van Eerdewegh $\mathbf{P}$, Little RD, Dupuis J, Del Mastro RG, Falls K, Simon J, Torrey D, Pandit S, McKenny J, Braunschweiger K, Walsh A, Liu Z, Hayward B, Folz C, Manning SP, Bawa A, Saracino L, Thackston M, Benchekroun Y, Capparell N, Wang M, Adair R, Feng Y, Dubois J, FitzGerald MG, Huang H, Gibson R, Allen KM, Pedan A, Danzig MR, Umland SP, Egan RW, Cuss FM, Rorke S, Clough JB, Holloway JW, Holgate ST, Keith TP. Association of the ADAM33 gene with asthma and bronchial hyperresponsiveness. Nature 2002;418:426-30.

27 Pastural E, Ersoy F, Yalman N, Wulffraat N, Grillo E, Ozkinay F, Tezcan I, Gedikoglu G, Philippe N, Fischer A, de Saint Basile G. Two genes are responsible for Griscelli syndrome at the same 15q21 locus. Genomics 2000;63:299-306.

28 Menasche G, Pastural E, Feldmann J, Certain S, Ersoy F, Dupuis S Wulffraat N, Bianchi D, Fischer A, Le Deist $F$, de Saint Basile G. Mutations in RAB27A cause Griscelli syndrome associated with haemophagocytic syndrome. Nat Genet 2000;25:173-6.

29 Heon E, Greenberg A, Kopp KK, Rootman D, Vincent AL, Billingsley G, Priston M, Dorval KM, Chow RL, Mclnnes RR, Heathcote G, Westall C, Sutphin JE, Semina E, Bremner R, Stone EM. VSX1: a gene for posterior polymorphous dystrophy and keratoconus. Hum Mol Genet 2002;11:1029-36.

30 Rabinowitz YS, Maumenee $I H$, Lundergan MK, Puffenberger E, Zhu D, Antonarakis S, Francomano CA. Molecular genetic analysis in autosoma dominant keratoconus. Cornea 1992;11:302-8.

31 Collier SA, Madigan MC, Penfold PL. Expression of membrane-type 1 matrix metalloproteinase (MT1-MMP) and MMP-2 in normal and keratoconus corneas. Curr Eye Res 2000;21:662-8.

32 Settle S, Marker P, Gurley K, Sinha A, Thacker A, Wang Y, Higgins K, Cunha G, Kingsley DM. The BMP family member Gdf7 is required for seminal vesicle growth, branching morphogenesis, and cytodifferentiation. Dev Biol 2001;234:138-50.

33 Watakabe A, Fujita $\mathrm{H}$, Hayashi M, Yamamori T. Growth/differentiation factor 7 is preferentially expressed in the primary motor area of the monkey neocortex. J Neurochem 2001;76:1455-64.

34 Lee KJ, Mendelsohn M, Jessell TM. Neuronal patterning by BMPs: a requirement for GDF7 in the generation of a discrete class of commissural interneurons in the mouse spinal cord. Genes Dev $1998 ; 12: 3394-407$. 